\title{
An Intervention Study for the Prevention and Control of Health Care-Associated Infection in the Critical Cares Area of a Tertiary Care Hospital in Saudi Arabia
}

\author{
Sanjay Kumar Gupta, Fahd Khaleefah AI Khaleefah ${ }^{1}$, Ibrahim Saifi AI Harbi', Fiaz Ahmed', Sinimol Jabar', Marilou Andal Torre', Sunitha Lorin Mathias ${ }^{1}$ \\ Department of Infection Prevention and Control, ${ }^{1}$ Al Rass General Hospital, Al Raas, Saudi Arabia
}

\section{Abstract}

Introduction: Healthcare-associated infections (HAIs) are an infection that patients acquire during receiving treatment and care for the medical or surgical problem. Objective: The objective of this study is to find the patterns of HAIs cases in the hospital and to know the impact of the intervention on prevention and control of health care associated infection. Methodology: This was prospective interventional study. Results: The majority of cases of HAIs was reported from intensive care unit $47 \%$. The most common site involved due to HAIs was catheter-associated urinary tract infection followed by central line-associated bloodstream infection. During the study period, around $28 \%$ reduction of cases were reported. During 6 months period (March to August 2016), around 540 cases were admitted in the critical care areas out of that 32 cases were reported as HAIs (5.9\%) for the same period from (March to August 2017) was (3.4\%), that difference came to be a statistically significant $\left(\chi^{2}=4.12, P=0.042, \mathrm{df}=1\right)$. Conclusion: This small study showed that strict implementation of care bundles with good compliance of hand hygiene, Personal protective equipment and antibiotic stewardship are helpful for prevention and control of hospital acquired infections. This study also demonstrated significant $(28 \%)$ reduction of hospital acquired infections during the study period.

Keywords: Critical care area, healthcare-associated infections, impact, intervention, prevention and control

\section{INTRODUCTION}

Healthcare-associated infections (HAIs) is an infection that patients acquire during receiving treatment and care for the medical or surgical problem. ${ }^{[1]} \mathrm{HAI}$ is a major concern for patient safety and its can lead to a prolonged hospital stay, long-term disability, the resistance of microorganisms, the extra financial burden to the healthcare system, more costs for patients and their families, and increases mortality. ${ }^{[2,3]}$ HAI is defined as: "An infection occurred in a patient during the process of care in a hospital or other health-care institution which was not present or incubating at the time of admission. This includes infections acquired in the hospital but appearing after discharge. ${ }^{[4]}$ The CDC and WHO surveys conducted in the 183 hospitals in the United States of America and observed 4\% HAIs, the most common types were pneumonia $(21.8 \%)$, followed by surgical site infections (21.8\%), and gastrointestinal infections (17.1\%). ${ }^{[5]}$ The study conducted by Moataz M. et al. in 2004 at Saudi Arabia about surveillance of nosocomial infections in the

\begin{tabular}{|l|l|}
\hline \multicolumn{3}{c|}{ Access this article online } \\
\hline Quick Response Code: & Website: \\
& www.ijccm.org \\
& \\
&
\end{tabular}

military hospital they observed $32.3 \%$ respiratory tract infection followed by $25.7 \%$ urinary tract infection (UTI) and $18.6 \%$ bloodstream infection (BSI). ${ }^{[6]}$ We estimated that in 2011 there were 648,000 patients reported 721,800 HAIs in U. S. acute care hospitals. On these HAIs cases, 33,848 pathogens reported, $87 \%$ were bacteria, and $13 \%$ were fungi. ${ }^{[6]}$ Over $15 \%$ of infections were polymicrobial. The most commonly isolated pathogens were coagulase-negative staphylococci aureus, Enterococcus species, Candida species, Escherichia coli, and Pseudomonas aeruginosa. ${ }^{[7]}$ In Europe, 5 million HAIs cases reported every year, of which $50,000(1 \%)$ are lethal and contribute to death in 135,000 cases $(2.7 \%) .^{[8,9]}$

Address for correspondence: Dr. Sanjay Kumar Gupta, Department of IPC, Al Rass General Hospital, Al Raas, Saudi Arabia. E-mail: sanjaygupta2020@gmail.com

This is an open access journal, and articles are distributed under the terms of the Creative Commons Attribution-NonCommercial-ShareAlike 4.0 License, which allows others to remix, tweak, and build upon the work non-commercially, as long as appropriate credit is given and the new creations are licensed under the identical terms.

For reprints contact: reprints@medknow.com

How to cite this article: Gupta SK, Al Khaleefah FK, Al Harbi IS, Ahmed F, Jabar S, Torre MA, et al. An intervention study for the prevention and control of health care-associated infection in the critical cares area of a tertiary care hospital in Saudi Arabia. Indian J Crit Care Med 2018;22:858-61. 


\section{Objectives}

The aim of this study is to find out the patterns of HAIs cases in the hospital and to know the impact of the intervention.

\section{Methodology}

A prospective intervention study was carried out for 6 months from March to August 2017, for the control of HAI in the hospital, the following intervention was done for the prevention and control of HAIs.

No sampling technique was applied all patients admitted in hospital during the study period were applied all interventions and reported. HAIs cases during the study period were taken as a sample for the comparison.

1. Basic infection control skill training to all health care workers regarding personal protective equipment's and others

2. Monitoring of aseptic precaution during any care and procedures

3. Day-to-day monitoring of hand hygiene compliance

4. Monitoring for strict implementation of preventive care bundles.

A bundle is a set of evidence-based practices that, when performed collectively and reliably, improve patient outcomes. Many bundle elements are well-established practices, combined in a structured protocol that is agreed on and is the responsibility of the whole clinical team.

\section{Components of care bundles}

Ventilator-associated pneumonia bundle (VAP Bundle).

a. Head elevation 30-45 degree. It helpful in preventing mucus collection and blockage of tube. This also increases the mucus drainage by gravity

b. Daily assessment of readiness to extubate

c. Daily oral care (chlorhexidine mouthwash)

d. Sedation vacation

e. VTE prophylaxis

f. Peptic ulcer disease prophylaxis

g. Keep the ventilator circuit free from condensation on every $2-4 \mathrm{~h}$

h. Use meticulous hand hygiene before and after contact with ventilator circuits

i. Change inline suction catheter system only when soiled or every $72 \mathrm{~h}$

j. Store oral suction device in a clean nonsealed plastic bag when not in use.

\section{Catheter-associated urinary tract infection bundle}

a. Hand hygiene and proper use of personal protective equipment's

b. Aseptic insertion techniques single use of lubricant sterile jelly

c. Meatus cleaning

d. Empty urine bag before three fourth fill

e. Urinary catheter bag hanging below the level of the bladder and not touching the floor

f. Urinary catheter has been continuously connected to a closed drainage system

g. Empty urinary catheter bag as a separate procedure into a clean container

h. Daily assessment of catheter requirement or need.

\section{Central line-associated bloodstream infection bundle}

a. Hand hygiene before touching the site

b. Daily inspection of the catheter

c. Port entry maintain closed all the time

d. Swab the diaphragm of the port with alcohol before using

e. Daily assessment of the possibility of removal.

Antibiotics stewardship program implementation.

The HAI data were compared with the same period of the previous year (2016), for that monthly data were collected for HAIs for 6 months during the study period (March-August 2017).

Collected data were entered in excel sheet and analyzed with the help of SPSS 20 (develop by IBM, USA), Value of $P \leq 0.05$ considered to be statistically significant.

Data were presented in the form of tables and graphs.

\section{RESULTS}

Table 1 shows that the majority of cases of HAIs reported from intensive care unit $47 \%$ followed by male medical wards $22 \%$, major reduction of cases shown in the medical department $50 \%$ due to intervention. Table 2 shows the most common site involved due to HAI was catheter-associated UTI (CAUTI) followed by central line-associated BSI (CLABSI). Graph 1 shows that during the study period around $28 \%$ reduction of cases were reported; Graph 2 shows a major reduction of cases in July 66\%. During 6 months (March to August 2016), around 540 cases were admitted in the critical care areas out of that 32 cases reported as HAIs (5.9\%) for the same period (March to August 2017) after the intervention around 680 cases were admitted in critical care areas out of the 23 cases reported as a HAIs $(3.4 \%)$, that difference came to be a statistically significant $\left(\chi^{2}=4.12, P=0.042, \mathrm{df}=1\right)$.

\begin{tabular}{|c|c|c|c|}
\hline & $\begin{array}{c}\text { HAls cases } \\
\text { (March-August) } \\
2016(\%)\end{array}$ & $\begin{array}{c}\text { HAls cases } \\
\text { (March-August) } \\
2017(\%)\end{array}$ & Total (\%) \\
\hline $\mathrm{ICU}$ & $13(40.62)$ & $11(47.82)$ & $24(43.63)$ \\
\hline MMW & $8(25)$ & $4(17.39)$ & $12(21.81)$ \\
\hline FMW & $6(18.75)$ & $4(17.39)$ & $10(18.18)$ \\
\hline $\mathrm{NICU}$ & $3(9.37)$ & $1(4.34)$ & $4(7.27)$ \\
\hline MSW & $2(6.25)$ & $2(8.69)$ & $4(7.27)$ \\
\hline Pediatrics & $0(0.0)$ & $1(4.34)$ & $1(1.81)$ \\
\hline Total & $32(100)$ & $23(100)$ & $55(100)$ \\
\hline
\end{tabular}

$\chi^{2}: 2.49$; Degrees of freedom: 5; Probability: 0.777. HAIs: Healthcareassociated infections; ICU: Intensive care unit; NICU: Neonatal intensive care unit; MMW: Male medical ward; FMW: Female medical ward; MSW: Male surgical ward 


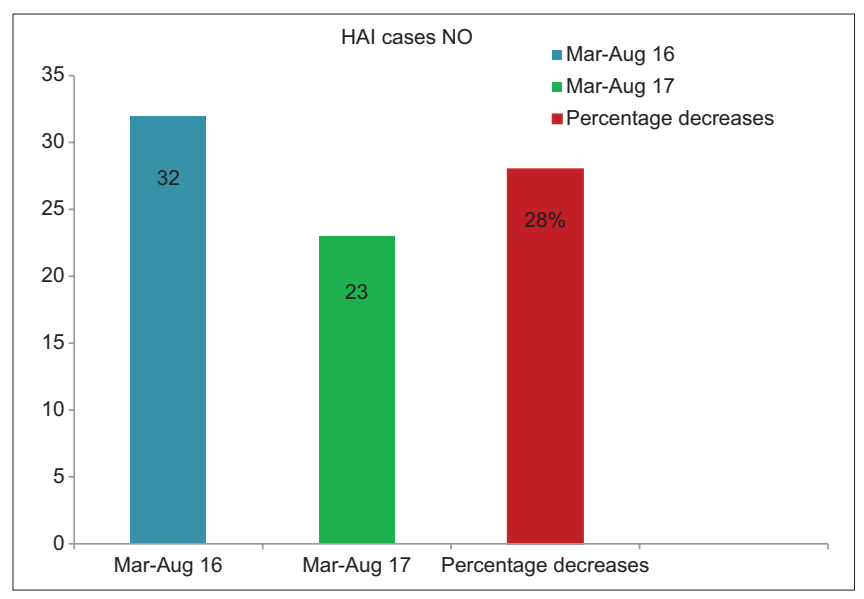

Graph 1: Total cases of health care-associated infections reported comparison) March-August (2016-2017). $\chi^{2}=4.12$, degrees of freedom $=1$, probability $=0.042$ (significant difference)

Table 2: Distribution of healthcare-associated infections cases according to the site of infection

\begin{tabular}{lccc}
\hline & $\begin{array}{c}\text { HAls cases } \\
\text { (March-August) } \\
\mathbf{2 0 1 6}(\%)\end{array}$ & $\begin{array}{c}\text { HAls cases } \\
\text { (March-August) } \\
\mathbf{2 0 1 7}(\%)\end{array}$ & Total (\%) \\
\hline CAUTI & $19(59.37)$ & $11(47.82)$ & $30(54.54)$ \\
VAP & $3(9.37)$ & $5(21.73)$ & $8(14.54)$ \\
CLABSI & $7(21.87)$ & $2(8.69)$ & $9(16.36)$ \\
HAP & $1(3.12)$ & $2(8.69)$ & $3(5.45)$ \\
BSI & $1(3.12)$ & $2(8.69)$ & $3(5.45)$ \\
SSI & $1(3.12)$ & $1(4.34)$ & $2(3.63)$ \\
Total & $32(100)$ & $23(100)$ & $55(100)$ \\
\hline
\end{tabular}

$\chi^{2}: 4.73$; Degrees of freedom: 5; Probability: 0.449. CAUTI: Catheterassociated urinary tract infection; VAP: Ventilator-associated pneumonia; BSI: Blood stream infection; CLABSI: Central line-associated BSI; SSI: Surgical site infection; HAP: Hospital-acquired pneumonia; HAIs: Healthcare-associated infections

If we compared data between pre- and post-intervention regarding HAI cases according to department and statistical test was applied no statistically significant difference were observed $\left(\chi^{2}=2.49, P=0.777, \mathrm{df}=5\right)$, data also compared between pre- and post-intervention regarding types of HAI according to site of involvement and statistical test was applied no statistically significant difference was observed $\left(\chi^{2}=4.73\right.$, $P=0.449, \mathrm{df}=5)$.

\section{Discussion}

This present intervention study was carried out to control of HAIs in the hospital, from March to August 2017. The intervention studies conducted by Abdraboh et al. regarding hand hygiene and HAI they found postintervention, significantly improvement in the knowledge and compliance results reduction of HAIs cases in the hospital. ${ }^{[10]}$

Cochrane review done by Gould DJ and others about intervention study to improve hand hygiene compliance in patient care. However, this systematic review found that only



Graph 2: Monthly percentage reduction of healthcare-associated infections cases from March to August 2017

a few high-quality, generalizable studies addressing the issue, in the present study, we also implemented stickt hand hygiene in critical areas. ${ }^{[1]]}$

The systemic review done by Silvestri L et al. regarding Adult Hospital and Ventilator-associated Pneumonia Guidelines: Eminence-rather than Evidence-based, author mention many lacuna in the ATS/IDSA guidelines for control of VAP not considering many facts, in the present study, we implemented evidence-based preventive care bundles and other intervention for prevention and control of HAIs in critical area.$^{[12]}$

\section{Conclusion}

The present study showed that strict implementation of care bundles with good compliance of hand hygiene, personal protective equipment, and antibiotics stewardship is helpful for prevention and control of hospital acquired infections. This study also revealed statistically significant $(28 \%)$ reduction of HAIs cases during the study period.

\section{Financial support and sponsorship}

Nil.

\section{Conflicts of interest}

There are no conflicts of interest.

\section{RefEREnCES}

1. Bates DW, Larizgoitia I, Prasopa-Plaizier N, Jha AK; Research Priority Setting Working Group of the WHO World Alliance for Patient Safety. Global priorities for patient safety research. BMJ 2009;338:b1775.

2. Burke JP. Infection control - A problem for patient safety. N Engl J Med 2003;348:651-6.

3. Allegranzi B, Bagheri Nejad S, Combescure C, Graafmans W, Attar H, Donaldson L, et al. Burden of endemic health-care-associated infection in developing countries: Systematic review and meta-analysis. Lancet 2011;377:228-41.

4. World Health Organization. Prevention of Hospital-Acquired Infections: A Practical Guide. Geneva: World Health Organization; 2002. p. 64.

5. Horan TC, Andrus M, Dudeck MA. CDC/NHSN surveillance definition of health care-associated infection and criteria for specific types of infections in the acute care setting. Am J Infect Control 2008;36:309-32.

6. Abdel-Fattah MM. Surveillance of nosocomial infections at a Saudi Arabian military hospital for a one-year period Ger Med Sci. 2005;3:9.

7. Magill SS, Edwards JR, Bamberg W, Beldavs ZG, Dumyati G, 
Kainer MA, et al. Multistate point-prevalence survey of health care-associated infections. N Engl J Med 2014;370:1198-208.

8. World Health Organization. Prevention of Hospital-Acquired Infections a Practical Guide. $2^{\text {nd }}$ ed. Switzexrland: World Health Organization Department of Communicable Disease Practical Guide for the Prevention of Health Care Associated Infections 2000.

9. Hidron AI, Edwards JR, Patel J, Horan TC, Sievert DM, Pollock DA, et al. NHSN annual update: Antimicrobial-resistant pathogens associated with healthcare-associated infections: Annual summary of data reported to the National Healthcare Safety Network at the Centers for Disease Control and Prevention, 2006-2007. Infect Control Hosp Epidemiol
2008;29:996-1011.

10. Abdraboh SN, Milaat W, Ramadan IK, Al-Sayes FM. Hand hygiene and health care associated infection: An intervention study. Am J Med Med Sci 2016;6:7-15.

11. Gould DJ, Moralejo D, Drey N, Chudleigh JH. Interventions to improve hand hygiene compliance in patient care. Cochrane Database Syst Rev 2010;8:9.CD005186.

12. Silvestri L, van Saene HKF, Milanese M, Fontana F, Gregori D, Oblach L, et al. Adult Hospital and Ventilator-associated Pneumonia Guidelines: Eminence- rather than Evidence-based, Am J Respir Crit Care Med 2006;173:388-416. 